\title{
Violentando y rehabilitando masculinidades de izquierda: La tortura sexual contra hombres y la terapia psicológica en las organizaciones de derechos humanos durante la dictadura de Pinochet, 1970s-1980s
}

\author{
Debilitating and Rehabilitating Leftist Masculinities: Sexual Torture of \\ Men and Psychological Therapy in Human Rights Organizations during \\ the Pinochet Dictatorship, 1970s-1980s
}

\author{
Brandi Townsend ${ }^{*}$
}

\begin{abstract}
Resumen: En los años setenta, varias organizaciones de derechos humanos incorporaron la terapia psicológica como parte de sus servicios para las personas afectadas por la violencia de Estado. Este artículo explora cómo ideas preconcebidas de género, sexualidad y política influyeron tanto en las maneras en que los ex presos políticos varones hablaron de sus experiencias, como en los conceptos y metodologías que los profesionales de la salud mental utilizaron para ayudarles a reconstruir sus subjetividades personales y políticas.
\end{abstract}

Palabras clave: masculinidad, tortura, Pinochet, psiquiatría, género, derechos humanos, homosexualidad

\begin{abstract}
Beginning in the mid-1970s in Chile, several human rights organizations incorporated psychological therapy as part of the services they offered to people affected by state violence. This article explores how preconceived ideas about gender, sexuality and politics influenced the ways in which male ex political prisoners spoke about their experiences, as well as how mental health professionals helped them reconstruct their personal and political subjectivities.
\end{abstract}

Key words: masculinity, torture, Pinochet, psychiatry, gender, human rights, homosexuality

Recibido: 6 febrero 2018

Aceptado: 14 abril 2018

* Estadounidense, Profesora Adjunta, Pontifica Universidad Católica de Chile, Instituto de Historia, brtownsend@uc.cl 
En Praga en 1976, el Colectivo Latinoamericano de Trabajo Psicosocial (COLAT), un grupo de profesionales de la salud mental que trabajaba en Bélgica con exiliados provenientes de América Latina, presentó en una conferencia sus conclusiones preliminares sobre los efectos de la tortura. Al tiempo que presentaron estadísticas y un resumen de sus casos y tratamientos, proporcionaron extractos de testimonios de pacientes para ilustrar las situaciones que estos habían enfrentado. Los ponentes, entre ellos el psicólogo chileno Jorge Barudy, destacaron el testimonio de un paciente de sexo masculino que había sido torturado sexualmente por agentes varones. Este paciente experimentó disfunción sexual después de su liberación y por ello buscó tratamiento psicológico. Era estudiante, casado, con veinticuatro años de edad, cuando fue detenido por los servicios de inteligencia de la Armada de Chile en Valparaíso. En su relato, describió a sus torturadores como homosexuales, e insistió en el estatus "anti-natural" de estos.

Buscaban tus puntos débiles. Yo he tenido siempre aversión a lo que es anti-natural. Los últimos días de tortura, me colocaron incluso pentotal sódico en el hospital, fui puesto con un equipo, al parecer, de oficiales homosexuales. Me ponían contra la pared, las manos amarradas, una mascarilla en la cara y una venda. Me ponían frente a la pared y me empezaban a manosear, a tocarme el sexo y a darme besos en el cuerpo. Incluso trataron de masturbarme. Cosa que no lograron. Cuando llegué la última vez a los cuarteles militares me hicieron desnudarme. Un oficial que era homosexual declarado me comenzó a allanar. Mi reacción fue de apretar los músculos y de mirar con furia. Era la única reacción, y decirle: --si estoy desnudo para qué me allana-- El problema de tortura no repercutió en ese momento mismo. Lo que yo sentía frente a los interrogadores puede ser asco, odio [...] pero cuando salí de la cárcel vino a repercutir con problemas, es decir, de orden de impotencia sexual. De repente me di cuenta que no había normalidad en la relación sexual con mi compañera. ${ }^{1}$

Después de pensar en sus problemas y en su posible origen, el ex preso político se dio cuenta de que lo que le "quebró los esquemas fue la actitud de los homosexuales que [lo] interrogaron"2. Tal vez ese hombre se centró en la supuesta aberración sexual de sus torturadores con el fin de entender una experiencia fuera de lo imaginable y así reafirmar el sentido de la masculinidad heterosexual y el poder que había perdido. En su relato, ligó la tortura sexual a los síntomas de la disfunción sexual que experimentó durante meses. Sin embargo, también hizo hincapié en su resistencia a su torturador: no tuvieron éxito masturbándolo. Apretó sus músculos para proteger su cuerpo desnudo durante el

\footnotetext{
${ }^{1}$ Énfasis subrayado en la fuente original. Colectivo Latinoamericano de Trabajo Psicosocial (COLAT), "Los problemas psíquicos provocados por la tortura en los refugiados chilenos y latinoamericanos", trabajo presentado al VI Congreso Médico Internacional de la Federación Internacional de Resistentes en Praga, Bélgica, ficha 0002004, Fundación Vicaría de la Solidaridad, Santiago, Chile, 1976, 16-17.

${ }^{2}$ Ibídem.
} 
allanamiento; una descripción que quizá señaló tácitamente la amenaza de la penetración forzada. Miró furiosamente al agente y cuestionó sus acciones, interrogando a sus torturadores. En el comienzo del testimonio, afirmó que "parecía" que sus torturadores eran homosexuales, y a lo largo de la narración de su experiencia, su evaluación llegó a ser más definitiva. Dijo que el agente que lo allanó fue un "homosexual declarado", y se refirió a los oficiales categóricamente como homosexuales a partir de entonces. Si ese paciente "siempre tenía una aversión a lo anti-natural", encontró una manera de hacer sentido de su experiencia - o al menos construir una narrativa sobre ella - planteando que los hombres que lo torturaron sexualmente eran anormales, y no necesariamente porque la tortura en sí fuera anti-natural. ${ }^{3}$

Los autores del estudio no hicieron ningún comentario; dejaron al testimonio hablar por sí mismo. Antes de la presentación, sin embargo, señalaron que varios de sus pacientes hombres habían sufrido síntomas causados por "abusos homosexuales" 4 . Este paciente se refirió a una experiencia que muchos hombres probablemente habían silenciado. Este caso, más aún, retrata agentes del régimen que violaron a otros hombres como homosexuales y la homosexualidad como "anti-natural". Lo que vemos en dicha narrativa es una confusión entre dos cuestiones muy distintas: la agresión o violencia sexual, por un lado, y el deseo sexual entre personas del mismo sexo, por otro. La homosexualidad es empleada retóricamente como un catalizador para la agresión "desviada" contra la masculinidad heterosexual. Con todo, los agresores de este preso político no eran sino agentes de la dictadura que practicaron la violencia sexual en los cuerpos de otros hombres con impunidad, al igual que lo hicieron con los cuerpos de las mujeres. Sin embargo, ni los presos políticos ni los profesionales de la salud mental tuvieron las herramientas conceptuales para entender la violencia política sexual ejercida por hombres contra otros hombres fuera del marco de la homosexualidad como perversión sexual.

Este trabajo examina las ideas acerca de la sexualidad, el género y la tortura sexual en los estudios realizados en los años 1970 y 1980 por los profesionales de la salud mental asociados a organizaciones de derechos humanos en Chile. Estas organizaciones crearon equipos interdisciplinarios compuestos principalmente por psicólogos, psiquiatras, asistentes sociales y sociólogos. Trabajaron juntos para ayudar a los presos y ex-presos políticos, sus familias y las familias de los desaparecidos y ejecutados. Su labor se materializó en documentos de trabajo, ponencias y estudios que fueron publicados principalmente después de la dictadura. Los equipos circularon su trabajo entre sí, y las organizaciones de derechos humanos enviaron sus boletines a otras organizaciones nacionales e internacionales. En el proceso, crearon un proceso de aprendizaje e intercambio entre instituciones orientado a investigar los medios más eficaces para atender a sus pacientes en un contexto de represión estatal, así como de recopilar documentación sobre denuncias de derechos humanos.

Como parte de un proyecto más extenso, la metodología de este artículo se basa en la revisión de aproximadamente 500 documentos de trabajo, publicaciones e informes

\footnotetext{
${ }^{3}$ Ibidem.

${ }^{4}$ COLAT, op.cit., 9.
} 
producidos por estos equipos. Analizo estos documentos junto con cientos de publicaciones e informes de organizaciones de derechos humanos, la prensa, testimonios de ex presos políticos, documentos del movimiento feminista y varias fuentes del gobierno de Allende y la dictadura militar. Adicionalmente, se incorporan dos entrevistas a profesionales que fundaron equipos de salud mental en las organizaciones de derechos humanos, no para indagar la construcción de la memoria, sino para llenar vacíos en la información disponible en los documentos. Para el propósito de este estudio, me enfoco en los primeros diez años de estos equipos de profesionales de la salud mental (1975-1985), que es el periodo en el que se encuentran más discusiones sobre la tortura sexual hacia hombres y sobre la homosexualidad en las fuentes.

No es claro por qué estos casos y debates no aparecen con tanta frecuencia después de mediados de los ochenta, pero se sugieren los siguientes factores: primero, los hombres en general hablaron poco de la tortura sexual, y los documentos que mencionan estos casos fueron producidos en los primeros años de la dictadura, cuando la represión era más extensa, y tanto los militantes como las organizaciones de derechos humanos aprendían y escribían sobre los distintos métodos de tortura que los agentes de la dictadura utilizaron. Segundo, con el auge del movimiento feminista a mediados de los ochenta, los profesionales de la salud mental — más que nada las mujeres- empezaron a prestar más atención a las experiencias de las mujeres militantes en sus estudios e incorporar nuevas ideas sobre el género y la sexualidad en sus conceptos y prácticas, lo que paradójicamente podría haber contribuido a invisibilizar las experiencias masculinas. Finalmente, las organizaciones de derechos humanos no siempre preservaron ni catalogaron sus archivos, ya que su prioridad fue atender a las personas y no desarrollar sistemas sofisticados de preservación de los documentos (quizás con la excepción de la Vicaría de la Solidaridad, la cual también perdió documentación en allanamientos). Algunas organizaciones, como FASIC, carecieron del financiamiento constante para poder catalogar y sistematizar completamente los documentos de sus archivos, y se encuentran ordenando y digitalizando estos documentos actualmente.

Me interesa estudiar particularmente cómo ex presos políticos y terapeutas comprendieron el problema de hombres torturando sexualmente a otros hombres, además de mujeres torturando a hombres. A menudo estos profesionales confundieron las ideas sobre el deseo entre personas del mismo sexo con la violencia, la agresión y la perversión. Así, exploro qué propósitos sirvieron tales caracterizaciones y patologías. De la misma forma, analizo lo que la tortura sexual de los hombres significó en este momento histórico, para comprender mejor las ideas sobre el género y la sexualidad que influyeron en la comprensión de la violencia del estado.

Planteo que tanto las narrativas de los ex presos políticos varones sobre la tortura sexual como las aproximaciones terapéuticas a este problema tienen su origen en ideas preconcebidas del género y la sexualidad que forjaron la cultura política de la izquierda a lo largo del siglo XX. Asimismo, los terapeutas fueron influenciados por construcciones de género recibidas durante su formación educacional, la cual adaptaron al contexto de la dictadura y violencia política masiva. Sostengo que los profesionales de la salud y las propias víctimas codificaron la experiencia masculina de la tortura sexual bajo parámetros 
de perversidad y anormalidad, y por medio de este discurso, de manera inconsciente, normalizaron ciertas formas de tortura sexual contra las mujeres.

Mi aproximación teórica de este problema se centra en la construcción sociocultural del género y la sexualidad. Judith Butler sostiene que el género funciona no solamente para imponer un significado cultural sobre los cuerpos sexuados. El género también produce las nociones mismas que establecen la supuesta naturaleza de los sexos biológicos. Es decir, el género establece la "verdad" según la cual los sexos se encuentran libres de influencias culturales. Por lo tanto, el binario masculino/femenino implica un entendimiento heterosexual del orden social, y relega la homosexualidad fuera de lo normal ${ }^{5}$. Como Michel Foucault argumentó, la construcción de discursos sobre "lo anormal" respaldó conceptos de normalidad. Estos discursos fueron, históricamente, formados por las ciencias humanas (incluyendo la psiquiatría y psicología) y otras instituciones que arbitraron las relaciones sociales, como el derecho. Asimismo, las personas utilizaron estos discursos para entender sus propias realidades y su sentido de sí mismos como parte de un colectivo humano ${ }^{6}$.

Estudios importantes sobre la tortura sexual se han centrado en las mujeres. Estos trabajos académicos, así como los informes de salud mental y de derechos humanos escritos durante la dictadura y la transición a la democracia, incluyeron a las mujeres en una narrativa de la militancia que se concentró en los hombres como los actores políticos que se sacrificaron por la revolución en la cárcel o en la tumba. Las mujeres no sólo lucharon por el retorno de los desaparecidos y sus maridos encarcelados y parientes varones, sino que también sufrieron la tortura brutal. Sin embargo, como Hillary Hiner ha argumentado, un binario de victimario-hombre / mujer-víctima surgió del discurso de los derechos humanos y se vio reforzado por las comisiones Rettig y Valech. Este binario marginó experiencias de los hombres con la tortura y abusos sexuales durante el régimen tanto cómo restó la agencia de las mujeres ${ }^{7}$. En el mismo sentido, analizo qué significó la tortura sexual de los hombres en este momento histórico, para comprender mejor las ideas sobre el género y la sexualidad que influyeron en las ideas sobre la violencia del estado. Aunque no es el tema de este trabajo, este enfoque también ayuda a la comprensión de los matices de la tortura. En efecto, la perspectiva de género permite socavar las estructuras patriarcales que hacen que sea difícil o imposible para muchas mujeres, y también para los hombres, hablar sobre sus experiencias con la tortura sexual.

No es mi intención restar valor a la labor de las organizaciones de derechos humanos, o criticar a los ex presos políticos que hablaron de las experiencias de violencia sexual perpetradas por el estado. Mi objetivo es, más bien, entender las premisas de los

\footnotetext{
5 Judith Butler, Gender Trouble, tercera edición, New York: Routledge, 2006, 10-12, 8-22.

6 Ibídem; Michel Foucault, The History of Sexuality Volume I: An Introduction, 2 ed., New York: Vintage, 1980, 54-57, 69-70, 81-102.

7 Hiner, op.cit., 54. Véase también: Inger Agger, "Sexual Torture of Political Prisoners: An Overview," Journal of Traumatic Stress 2:3, 1989, 305-314; Ximena Bunster-Burotto, "Surviving Beyond Fear: Women and Torture in Latin America", Women and Change in Latin America, editado por June Nash y Helen I. Safa, South Hadley, Massachuetts, Estados Unidos, 1986, 297-395.
} 
conceptos de género, sexualidad y violencia que determinaron su forma de hablar y escribir sobre estas experiencias. Mediante el análisis de estas nociones en su contexto histórico, podemos entender mejor la complejidad del movimiento de derechos humanos en Chile.

El artículo se divide en tres partes. La primera resume la historia del género y la sexualidad en las políticas de la izquierda y en los conceptos de salud mental del siglo XX. La segunda explora el rol del testimonio terapéutico en denunciar las violaciones a los derechos humanos para reconstruir las subjetividades hetero-masculinas. Finalmente, la tercera parte discute los discursos de normalidad y anormalidad sexual empleados en testimonios sobre la violencia del estado.

\section{El género, la política y la salud mental en el Chile del siglo XX}

\section{Las culturas políticas de la izquierda y la modernización y el Estado}

Numerosos estudios académicos han demostrado que el género jugó un papel innegable en la consolidación de las culturas políticas de izquierda, tanto en Chile como en otros países latinoamericanos. La "modernización del patriarcado" adaptó ideas arraigadas del patriarcado para implementar proyectos de reforma social y modernización nacional ${ }^{8}$. En Chile, los gobiernos del Frente Popular forjaron alianzas entre las elites, la clase media y la clase trabajadora, utilizando ideas compartidas sobre el trabajo, la familia y las relaciones de poder entre hombres y mujeres. Basaron sus programas en los códigos morales establecidos por los partidos Socialista y Comunista: los hombres trabajadores debían ser jefes de hogar responsables que gastaban su dinero en sus familias, en vez del alcohol, las apuestas, los deportes de sangre y otras mujeres. Además, debían abstenerse de ejercer la violencia contra sus esposas e hijos. Las mujeres, por su parte, debían mantener hogares higiénicos y eficientes, así modernizando la esfera doméstica ${ }^{9}$.

En las décadas de los sesenta y setenta, los gobiernos de Eduardo Frei Montalva y de Salvador Allende Gossens también hicieron uso de ideas de género para consolidar proyectos de desarrollo e incluir a las masas en la participación política y social. Por ejemplo, promovieron la noción de la paridad de género en los matrimonios como parte integral de la Reforma Agraria. Sin embargo, los programas estatales educaron a los hombres campesinos a "ser sus propios jefes" por medio de la formación política y el uso de nuevas tecnologías agrícolas. En cambio, la participación política asignada a las mujeres fue basada mayoritariamente en sus roles como madres y esposas ${ }^{10}$. En términos generales,

\footnotetext{
${ }^{8}$ Mary Kay Vaughan, "Modernizing Patriarchy: State Policies, Rural Households, and Women in Mexico, 1930-1940", Elizabeth Dore y Maxine Molyneux (eds.), Hidden Histories of Gender and the State in Latin America, Durham, Duke University Press, 2000, 194-214.

${ }^{9}$ Karin Rosemblatt, Gendered Compromises: Political Cultures and the State in Chile, 1920-1950, Chapel Hill, University of North Carolina Press, 2000, 27-57.

${ }^{10}$ Heidi Tinsman, Partners in Conflict: The Politics of Gender, Sexuality, and Labor in the Chilean Agrarian Reform, 1950-1973, Durham, Duke University Press, 2002, 82-170.
} 
la Unidad Popular apeló a los hombres como los protagonistas políticos, los que tenían el deber de educar a las mujeres en la política. Después de "conquistarlas" para la revolución, las mujeres podrían realizar su propia emancipación. Por lo tanto, la liberación de las mujeres sería un resultado del socialismo, no necesariamente parte constitutiva del proceso revolucionario ${ }^{11}$. El hombre trabajador, entonces, fue el foco de la vía chilena al socialismo, ya que el socialismo en general buscó levantar a los trabajadores, siendo que la mayoría de estos eran hombres. Las mujeres de la clase trabajadora, en cambio, se beneficiaron de manera más indirecta de los programas de la Unidad Popular ${ }^{12}$.

Otros estudios han iluminado los supuestos de género y sexualidad en distintos partidos políticos de la izquierda, además de las tensiones que esto generó entre distintas generaciones de militantes. Por ejemplo, los militantes jóvenes del Movimiento de Izquierda Revolucionaria (MIR) adoptaron nociones de la relación entre el género y la política que fueron similares a las del Hombre Nuevo de Cuba. Este hombre nuevo priorizó la liberación de todas las familias, sin abandonar a su propia familia ${ }^{13}$. Al mismo tiempo, el MIR generalmente rechazó las ideas de masculinidad respetable que había, en gran parte, formado la cultura política de los primeros partidos marxistas a lo largo del siglo XX. El liderazgo del MIR - mayormente hombres jóvenes de clase media- recurrió a otros símbolos históricos de la masculinidad chilena como "el huaso" y "el roto macanudo". Estas figuras representaron el hombre que resistía la autoridad y las prescripciones de disciplina del jefe, el patrón, y el Estado. Los hombres homosexuales, sin embargo, fueron excluidos del MIR. Esto calzó con las ideologías y políticas internacionales de los partidos marxistas, que consideraron que los homosexuales eran un producto del exceso burgués ${ }^{14}$.

Los partidos tradicionales de la izquierda en Chile también denigraron la homosexualidad. Caracterizaron a los jóvenes hombres con el pelo largo como afeminados y homosexuales, y los acusaron de carecer de disciplina personal. La UP mantuvo, en términos generales, una posición conservadora en cuanto a los jóvenes, destacando los valores tradicionales de los partidos marxistas que enfatizaron la responsabilidad familiar y el autocontrol sexual, en un momento histórico en que los jóvenes comenzaban a cuestionar estos mismos principios ${ }^{15}$. Aunque organizaciones como las Juventudes Comunistas tomaron actitudes más abiertas en cuanto al sexo antes del matrimonio, la píldora

\footnotetext{
11 Sandra McGee Deutsch, "Gender and Sociopolitical Change in Latin America", Hispanic American Historical Review 71:2, May 1991, 292-304; Teresa Valdés, Centros de Madres, 1973-1989. Sólo disciplinamiento? Santiago, FLACSO, 1989, 12-30.

12 Margaret Power, "La Unidad Popular y la Masculinidad”, La ventana 6, 1997, 250-270.

${ }^{13}$ Un pasaje del ensayo de Ernesto "Che" Guevara, "El hombre y el socialismo en Cuba", fue imprimido en Estrategia: Revista Teórica, Movimiento de Izquierda Revolucionaria, Septiembre de 1966, 1-16.

${ }^{14}$ Florencia Mallon, "Barbudos, Warriors, and Rotos: The MIR, Masculinity, and Power in the Chilean (ed), Durham, Duke University Press, 2000, 179-215. Véase también: Olga Ruíz, "Mandatos militantes, vida cotidiana y subjetividad revolucionaria en el Movimiento de Izquierda Revolucionaria de Chile (19651975), Revista Austral de Ciencias Sociales 28, 2015, 163-182.

${ }^{15}$ Patrick Barr-Melej, Psychedelic Chile: Youth, Counterculture, and Politics on the Road to Socialism and Dictatorship, Chapel Hill, University of North Carolina Press, 2017, 8-14.
} 
anticonceptiva y las separaciones maritales, sus cuestionamientos no se extendieron hacía la homosexualidad 16 .

En resumen, las políticas del Estado de Bienestar, la UP y otros partidos y organizaciones políticas de la izquierda, reafirmaron ideas de género basadas en modelos del hombre trabajador, jefe de hogar y protagonista político, y de la mujer madre y esposa moderna, "compañera" de los hombres en la participación política. Aunque en los sesenta y setenta los jóvenes empezaron a desafiar las tradiciones de comportamientos sexuales y los roles de género, la homosexualidad siguió siendo tabú en muchos círculos. La masculinidad, además, fue entendida como heterosexual, y los hombres homosexuales (y los que fueron presumidos como homosexuales) fueron marginados de la visión política tanto de la izquierda tradicional como de la de los jóvenes partidos y movimientos, siendo supuestamente débiles, afeminados y careciendo de la disciplina moral y sexual necesarias para consolidar un proyecto revolucionario.

\section{De profesionales del Estado de Bienestar a especialistas de la salud mental bajo la Dictadura}

Los programas del Estado de Bienestar, además de promover ciertos comportamientos basados en ideas de género, sostuvieron la creación de una nueva clase de profesionales quienes abogaban por la clase trabajadora. Estos programas constaron de médicos, higienistas, enfermeras sanitarias y trabajadoras sociales que jugaron roles esenciales en las reformas sociales. Fueron mediadores entre el Estado y la clase trabajadora, además de modelos para la masculinidad y femineidad respetable ${ }^{17}$.

Los profesionales de la salud mental que trabajaron con organizaciones de derechos humanos fueron formados como parte de esta larga tradición de la medicina social. Aunque no fueron personajes centrales de los proyectos de bienestar, los médicospsiquiatras habían demostrado un interés especial en la llamada "higiene mental" de la población desde principios del siglo. En esta época de reforma social en América Latina, las ciencias humanas utilizaron ciertos conceptos de la eugenesia. Sin embargo, a diferencia de países como los Estados Unidos, los médicos y reformadores sociales postularon que la salud de la raza dependía no solamente de la herencia genética, sino también del ambiente, cuya higienización podría resultar en fortalecer "la raza chilena" y por tanto, la nación18.

Las visitadoras sociales fueron figuras importantes en asesorar e intervenir en la adecuación y la higiene de los hogares. La primera escuela de trabajo social fue establecida en 1925. La profesión fue exclusivamente femenina, ya que las características de abnegación y sacrificio, empatía y compasión fueron consideradas como naturalmente

\footnotetext{
${ }^{16}$ Alfonso Salgado, "A Small Revolution: Family, Sex, and the Communist Youth of Chile during the Allende Years (1970-1973)," Twentieth Century Communism 8 (January 2015): 62-88.

${ }^{17}$ Rosemblatt, op.cit., 123-148.

18 Silvana Vëto, "Higiene Mental Infantil y Psicoanálisis en la Clínica de Conducta, Santaigo de Chile, 19361938”, ACSLEPIO: Revista de Historia de la Medicina y de la Ciencia, 69:2, Julio-diciembre 2107, 6-7; Karin Rosemblatt, "Sexuality and Biopower in Chile and Latin America", Political Power and Social Theory 15, 2002, 229-262.
} 
propias de las mujeres. Como actoras de la nueva clase de "profesionales del bienestar"19, las visitadoras sociales visitaron las casas de los pobres y la clase trabajadora como parte de los nuevos programas estatales. En las primeras décadas de su profesionalización, el Servicio Social se enfocó en ayudar a los pobres a adaptarse a vivir en una sociedad moderna. No obstante, según las premisas de la profesión en ese entonces, la capacidad de aclimatarse a los nuevos criterios de comportamiento, higiene y organización del hogar dependía menos de las desigualdades estructurales de poder en la sociedad que de las habilidades intrínsecas o cualidades personales de los pobres. De esta forma, las visitadoras sociales contribuyeron a "patologizar" a las personas pobres por su dificultad a adaptarse socialmente. Asimismo, las visitadoras sociales impulsaron a los sectores populares a cumplir con las normas de género implícitas en o requeridas por los programas estatales ${ }^{20}$.

No obstante, con los cambios políticos y sociales de los sesenta y setenta, las visitadoras sociales reflexionaron críticamente sobre su profesión. Aplicaron lo que aprendieron trabajando con los sectores populares, e intentaron respetar el conocimiento local que estos desarrollaron. Su aproximación fue trabajar con estas comunidades para efectuar el cambio social y la democratización de la sociedad, alejándose de la patología individual. Tampoco buscaron victimizar a los pobres. En lugar de ello, plantearon que el Estado debería proveer los recursos para que las personas y comunidades pudieran levantarse a sí mismas ${ }^{21}$. Las visitadoras sociales formadas en esta época llevarían su conocimiento a las organizaciones de derechos humanos, siendo ellas quienes recibieron a las personas y las derivaron a los servicios adecuados de acuerdo a su situación. También, las visitadoras sociales (llamadas desde entonces "asistentes sociales") formaron parte de los equipos de salud mental y realizaron talleres en las comunidades, terapia psicológica y estudios y ponencias en conferencias.

La mayoría de los profesionales de la salud mental que luego trabajaron con organizaciones de derechos humanos estudiaron en la Universidad de Chile o la Universidad Católica en los sesenta y setenta. Se nota la gran influencia del médicopsiquiatra Armando Roa Rebolledo en las publicaciones del cuerpo docente y la administración de los programas de psiquiatría. Roa era profesor titular de la Universidad de Chile y profesor de la Universidad Católica, además del director de la cátedra de psiquiatría en la Universidad de Chile y editor general de la Revista Chilena de Psiquiatría Clínica. Más aún, Roa escribió un manual de psiquiatría en 1959 en el cual discutió el "homosexualismo" como una "perversión sexual", una categoría que también incluyó el travestismo, la bestialidad, el exhibicionismo y la necrofilia, entre otros ${ }^{22}$.

Al mismo tiempo, hay que reconocer que, hasta 1973, la homosexualidad era considerada una enfermedad mental en el Manual Diagnóstico de Trastornos Mentales de la Asociación Estadounidense de Psiquiatría (American Psychiatric Association). La

\footnotetext{
${ }^{19}$ Este término proviene de Karin Rosemblatt, op.cit., 3.

${ }^{20}$ Rosemblatt, op.cit., 1-25; María Angélica Illanes, Cuerpo y sangre de la polítia: La construcción social de las Visitadoras Sociales, 1887-1940, Santiago, LOM, 2007, 12-30; 245-346.

${ }^{21}$ María Angélica Illanes, "La 'pedagogía crítica' de las trabajadoras sociales en el Chile de los sesenta y setenta", Mujeres. Historias chilenas del siglo XX, Julio Pinto Vallejos (ed.), Santiago: LOM, 2010, 9-34.

${ }^{22}$ Armando Roa, Psiquiatría, Santiago, Editorial Andrés Bello, 1959, 182-186.
} 
decisión de eliminarla de la lista de patologías fue provocada mayormente por el activismo gay en los Estados Unidos en los años sesenta y setenta, además de los estudios de Alfred Kinsey y Evelyn Hooker sobre la homosexualidad masculina. No obstante, este cambio fue rechazado por muchos profesionales de la salud mental en Chile y el mundo, y además, nuevos diagnósticos que fueron creados camuflaron el sesgo contra el deseo sexual entre personas del mismo sexo hasta $1987^{23}$.

En respuesta a estos cambios, Roa publicó un libro en 1984 criticando el nuevo manual, especialmente la noción que los homosexuales que estaban satisfechos con su orientación sexual eran considerados como "psíquicamente normales", así poniendo en cuestión la autoridad del médico psiquiatra en diagnosticar la llamada enfermedad. Roa sostuvo que, "con ese modo de pensar, lógicamente habría de creerse también que los maníacos, felices con su alegría desorbitada, son normales, y quizás si deberían estimarse normales una serie de conductas con las cuales gozan sus autores y que la mayoría de los seres humanos no trepida en ubicar entre lo patológico"24. Además, Roa afirmó que "Si el contacto de lo mismo con lo mismo en el sexo fuera tan normal como el contacto del mismo con lo otro (masculino y femenino), no se ve la necesidad de los sexos. . . ." así poniendo en jaque "la diferenciación de los sexos"25. Estas declaraciones respaldan la teoría de Butler, mencionada arriba: el orden de género basado en el binario de hombre/mujer fue moldeando y perpetuando la "verdad" biológica de la heterosexualidad, y así marginando cualquier otro tipo de deseo sexual o expresión de género. Según Juan Rolando Cornejo, esta patologización de la homosexualidad no fue seriamente cuestionada en la comunidad psiquiátrica chilena hasta principios de los noventa, fecha que coincide con la vuelta a la democracia y los primeros movimientos de derechos LGBT en el país ${ }^{26}$.

Estas conceptualizaciones de los roles de género y la sexualidad, basadas en la premisa de la heterosexualidad, se notan en la malla curricular y en los talleres de extensión ofrecidos por la Universidad de Chile en los años 1960 y 1970, los cuales destacaron las distinciones entre hombres y mujeres. Un taller de 1977, "Aspectos psicológicos del varón adulto", tocó los temas de "el amor erótico como experiencia para la plenitud masculina", "el trabajo como configuración de lo masculino", "vivencia de la sexualidad en el varón", y "el hombre ante su familia". El taller sobre la psicología de las mujeres, por otro lado, se enfocó en la mujer como "creadora de espacios vitales" y "trabajo y moda" y "esencia de la femineidad", apuntando a la dicotomía de los hombres como protagonistas sociales y sexuales, y las mujeres como seres que forjaron y mantuvieron la esfera privada ${ }^{27}$.

\footnotetext{
${ }^{23}$ Jack Drescher, “Out of DSM: Depathologizing Homosexuality”, Behavioral Sciences 5: 4, Basel, Suiza, diciembre 2015, 565-575, disponible en: https://www.ncbi.nlm.nih.gov/pmc/articles/PMC4695779/

${ }^{24}$ Armando Roa, Nueva visión de las enfermedades mentales. Disfernias, personalidades paranormales, homosexualidad. Crítica al DSM II, Santiago, Editorial Universitaria, 1984, 15.

${ }^{25}$ Ibídem, 16.

${ }^{26}$ Juan Rolando Cornejo, "Configuración de la homosexualidad medicalizada en Chile", Sexualidad, salud y sociedad 9, Rio de Janeiro, enero de 2011. http://www.scielo.br/scielo.php?script=sci_arttext\&pid=S198464872011000400006. Cornejo también destaca la influencia de Roa en la patologización de la homosexualidad en el contexto chileno.

27 “Cursos de Extensión”, Revista de Psiquiatría Clínica, Vol. XIV, 1977, 75.
} 
Estas ideas sobre los roles de género siguieron siendo reproducidas en los estudios académicos a fines de los 1970. Por ejemplo, Angélica Paredes, Psicóloga Jefe del Departamento de Psiquiatría y Salud Mental de la Universidad de Chile, recurrió principalmente a las publicaciones y las clases de Roa en un artículo titulado "Reflexiones en torno a la psicología de la mujer". Aunque reconoció que muchos factores ambientales jugaban un rol en la construcción de los yoes femeninos, sostuvo que las mujeres de aquella época tenían trastornos psicológicos porque negaron realizar la construcción de su yo de acuerdo a la naturaleza de su sexo, la cual estaba ligada a la casa y al mundo privado. La autora destaca que este problema estuvo exacerbado por el creciente movimiento feminista, el cual animó a las mujeres a construir su yo de acuerdo al modelo masculino para lograr la igualdad con los hombres. Esto, según la autora, les provocaba perturbaciones psíquicas porque no alcanzaban el nivel de los rendimientos masculinos, ni lograban auto-realizarse como mujeres ${ }^{28}$. Ya que los profesionales que luego trabajaron con organizaciones de derechos humanos fueron formados mayormente en la Universidad de Chile y la Universidad Católica durante los 1960s y 1970, es muy probable que fueron influenciados de alguna manera por los textos y clases de Roa y sus pares, como Paredes.

Además de asistentes sociales y psiquiatras, los equipos de salud mental de las organizaciones de derechos humanos constaron de psicólogos y sociólogos. Todos tomaron cursos de psicoanálisis, el cual fue la base de la formación en psiquiatría. Elizabeth Lira, socióloga y miembro del equipo de FASIC (y luego fundadora del Instituto Latinoamericano de Salud Mental y Derechos Humanos), recuerda haber leído principalmente los textos de Freud en sus clases en la Universidad Católica ${ }^{29}$. Al mismo tiempo, la carrera de sociología de la UC se enfocó en los textos de Carlos Marx para interpretar la historia y las realidades actuales de la sociedad, la política y la economía. Por su parte, la malla curricular de licenciatura en psicología enfatizó la familia y la infancia, además de la criminología ${ }^{30}$. El psicólogo Sergio Lucero se especializó en criminología, y fue despedido en 1973 del Hospital de Carabineros donde trabajaba. Después, trabajó en el Comité Pro-Paz y luego en la Vicaría de la Solidaridad ${ }^{31}$.

Tanto como la izquierda política, la psiquiatría y las disciplinas relacionadas fortalecieron los binarios de masculino/femenino y heterosexual/homosexual a lo largo del siglo XX. La generación de profesionales de la salud mental que trabajaron en las organizaciones de derechos humanos en los 1970 y 1980 fueron entrenados como parte de este mundo de saberes y tradiciones político-sociales. Aunque esto no es sorprendente, dado el contexto histórico, es clave para entender cómo los profesionales y los militantes

\footnotetext{
${ }^{28}$ Angélica Paredes, "Reflexiones en torno a la psicología de la mujer", Revista de Psiquiatría Clinica, Vol. XVI-2, 1979, 41-47.

${ }^{29}$ Entrevista personal con Elizabeth Lira, Santiago, junio de 2013.

${ }^{30}$ Esta información proviene de las mallas curriculares de los 1960 y 1970 en la Universidad de Chile y la Universidad Católica. Sobre el uso de Marx y Freud en la salud mental, véase: Nancy Caro Hollander, Love in a Time of Hate: Liberation Psychology in Latin America, New Brunswick, Rutgers University Press, 1997, 17-109.

${ }^{31}$ Sergio Lucero, Curriculum vitae, Fundación Viacaría de la Solidaridad, Santiago, Chile, 1990.
} 
abordaron el problema de la tortura sexual contra los hombres-realizada tanto por hombres como por mujeres.

\section{La salud mental en las organizaciones de derechos humanos}

Las primeras organizaciones de derechos humanos que prestaron servicios de salud mental a las víctimas sobrevivientes de la violencia estatal y sus familias fueron la Vicaría de la Solidaridad y la Fundación de Ayuda Social de las Iglesias Cristianas (FASIC). Estas organizaciones también ofrecieron asistencia jurídica a los presos políticos y ayudaron a miles de personas en su búsqueda de familiares desaparecidos y encarcelados. Se prestaron servicios para aliviar las situaciones resultantes de la represión política, como préstamos para estudios universitarios o para abrir pequeños negocios, y apoyo en el proceso de exilio y retorno ${ }^{32}$.

El Comité Pro-Paz, el precursor de la Vicaría, fue fundado en 1973 por los líderes de las iglesias protestantes, la comunidad judía y la Iglesia Católica, pero el régimen militar obligó a su cierre en noviembre de 1975 cuando los militares se enteraron de que algunos sacerdotes habían participado en la protección de militantes del MIR. El Arzobispo de Santiago, Raúl Silva Henríquez, fundó la Vicaría de la Solidaridad en enero de 1976 para continuar con la labor del Comité Pro-Paz. FASIC se fundó en abril de 1975 como una colaboración entre la Iglesia Católica, las iglesias protestantes y la comunidad judía a finales de 1970. Tanto la Vicaría como FASIC integraron equipos permanentes de profesionales que prestaron servicios médicos y de salud mental. Durante los años 80, otras organizaciones semejantes (aunque seculares), como el Comité de la Defensa de los Derechos del Pueblo (CODEPU) formaron sus propios equipos de salud mental. Además, algunas organizaciones fueron establecidas específicamente para proporcionar servicios médicos y de salud mental ${ }^{33}$. Entre 1975 y 1989, estas organizaciones prestaron servicios de salud mental a aproximadamente 32,000 a 42,000 personas afectadas por la violencia de Estado $^{34}$.

\footnotetext{
32 Mario Garcés y Nancy Nicholls, Para una historia de los derechos humanos en Chile. Historia institucional de la Fundación de Ayuda Social de la Iglesias Cristianas, 1975-1991, Santiago, LOM, 2005, 28-52, 105-107.

${ }^{33}$ Vicaría de la Solidaridad, "Del Comité para la Paz a la Vicaria de la Solidaridad. La institucionalización de los derechos humanos", Archivo Vicaría de la Solidaridad, Santiago, ca. 1978. Una de las organizaciones más significativas fue el Comité for la Defensa de los Derechos del Pueblo y su equipo médico y de salud mental, Equipo de Denuncia, Investigación, y Tratamiento, y su Núcleo Familiar (CODEPU-DITT). El Centro de Investigación, y Tratamiento del Stress (CINTRAS) se formó para tener un equipo de profesionales que se enfocaron en los casos más complicados de trastornos psicológicos. El Instituto Latinoamericano de Salud Mental y Derechos Humanos (ILAS) su fundó en 1988, y su equipo se concentró en la investigación y publicación de estudios sobre la salud mental y violencia de Estado en Chile, mientras prestaron terapia a los sobrivivientes y sus familiares. Información sobres los enfoques de la organización vienen de la entrevista personal con Elizabeth Lira, Santiago, abril de 2013.

${ }^{34}$ Coordinadora de Equipos de Salud Mental, "Colaboración en las areas de reparación de los daños a la salud y la salud mental en las personas afectadas por la represión política y la violación de los derechos humanos
} 
Si bien los profesionales de salud mental basaron su práctica en su formación universitaria, también desarrollaron sus conocimientos, conceptos y prácticas a través de años de enfrentar las condiciones extremas de represión política y la violencia de Estado, para lo cual la educación universitaria no los había preparado. La experiencia con la represión estatal y el diálogo con las víctimas sobrevivientes y sus familias jugaron el papel más profundo en la formación de conceptos y prácticas para ayudar a los miles de chilenos que enfrentaban un trauma colectivo.

Estos profesionales de la salud mental argumentaron que el régimen de Pinochet utilizó la tortura para quebrantar las lealtades de los militantes de izquierda con los partidos políticos y colectivos sociales. Según ellos, la tortura, como trauma psicológico, provocó que los individuos que la experimentaron se encerrasen en sí mismos, para dejar de confiar en los demás, volviéndose individualistas y celosos sobre-protectores de sus cuerpos y mentes. Además, la tortura sexual fue uno de los métodos más eficaces para convertir ciudadanos activos y saludables en individuos solitarios, neuróticos y reducidos a una fracción de lo que habían sido antes de ser apresados y torturados. Así, la tortura facilitó la construcción de una mentalidad acorde con el neoliberalismo e individualismo, en vez de reforzar una subjetividad anclada en una forma de democracia social. Al mismo tiempo, los profesionales de la salud mental instaron a que la reconstrucción de las subjetividades individuales - $\mathrm{o}$ los yoes de estos - fuese un proceso vital en la lucha colectiva por la recuperación de la democracia en Chile ${ }^{35}$.

\section{Denunciar la tortura y rehabilitar la masculinidad heterosexual}

Para facilitar la sanación psicológica de los ex presos políticos traumatizados, algunos profesionales de la salud mental, principalmente aquellos de FASIC y CODEPU, plantearon que el acto de crear un testimonio escrito, que idealmente sería usado públicamente para denunciar las violaciones contra los derechos humanos, era un paso clave para reconstruir la subjetividad, y como parte de esto, reconectarse a la política a través de una denuncia pública. Según varios profesionales de la salud mental, esto apoyaba la progresión en la salud mental de una persona con dificultad de expresarse por no haber podido narrar la experiencia traumática ni abordado su significado. De acuerdo a estos profesionales, el testimonio escrito señalaba que la psique del ex preso político traumatizado ya no estaba rota, y esta persona entonces podría participar como un ciudadano y un ser "evolucionado", por haberse vinculado a una lucha político-social.

del periodo dictatorial", Santiago, Biblioteca CINTRAS, mayo de 1990. El estimado de este equpio es amplio porque tomaron en consideración la pérdida de documentos durante el allanamiento de la Vicaría en 1985.

${ }^{35}$ Casi todos los estudios de salud mental mencionan los efectos del neoliberalismo en conjunto con los de la tortura. Un buen ejemplo del argumento citado arriba se encuentra en Adriana Maggi V. "Trauma psíquico, trauma social", Trabajo presentado al XX Congreso de Sociedad Interamericana, Caracas, Venezuela, Archivo FASIC, Santiago de Chile, 1986. Véase también: Berta Bel, "La tortura: efectos sociales y apoyo a la supervivencia", trabajo presentado en Buenos Aires al simposio "Tortura en America Latina", Archivo FASIC, Santiago, 1985; CODEPU-DITT, Persona, Estado, Poder. Estudios sobre salud mental. Chile, 19731989, Santiago, Edición Sergio Pesutic, 1989, 257-262. 
Para lograr estos fines, dos profesionales de la salud mental del Programa Médico Psiquiátrico de FASIC, plantearon un método que llamaron "el testimonio". Publicaron un estudio en 1980 bajo los seudónimos Ana Cienfuegos y Cristina Monelli y combinaron conceptos del psicoanálisis y del existencialismo para ayudar a los pacientes a convertir su trauma indecible en denuncias públicas de violaciones a los derechos humanos. A través de una serie de sesiones de terapia, los pacientes hablaban sobre sus experiencias con la tortura y las consecuencias de la violencia de Estado, las cuales los terapeutas registraban en una grabadora de voz. Las grabaciones y los documentos transcritos podrían ser utilizados tanto para contener el horror de la experiencia traumática como para denunciar violaciones de derechos humanos ante las organizaciones internacionales, los tribunales y las futuras comisiones de verdad. El método también permitió que los terapeutas recopilaran evidencia de algunos de los casos más extremos de tortura y trauma psicológico resultante, y argumentaron que otros presos políticos y sus familias enfrentaban las mismas o similares situaciones ${ }^{36}$.

El estudio explica que verbalizar un trauma indecible y convertir un testimonio oral en un texto escrito facilitaría la inversión de lo que las autoras llamaban un "ciclo regresivo" o un "ciclo hacia el deterioro". Ellas y otros terapeutas caracterizaron ese ciclo por la ruptura de los vínculos sociales, la pérdida del proyecto político, la ansiedad, la depresión, la agresión y la presencia abrumadora de síntomas psicosomáticos como la disfunción sexual y la pérdida de habilidades motoras, como la capacidad lingüística. El lenguaje ayudó al paciente a representar la experiencia traumática y organizarla en una narrativa. El método testimonio "guiaba y contenía la agresión [del paciente]", por medio de elaborar experiencias de violencia de Estado a través del lenguaje. Por último, los pacientes podrían reparar los lazos sociales mediante la constatación de que otros habían sufrido situaciones similares y que su testimonio podría servir como una herramienta para la resistencia política en la denuncia de violaciones de derechos humanos a nombre de sí mismos y de los demás. Las terapeutas afirmaron que, en muchos casos, esta práctica vinculó a los pacientes a sus proyectos políticos anteriores ${ }^{37}$.

El concepto del "hombre concreto" de las autoras fue la idea central del método del testimonio. Citando las políticas de la Unidad Popular, las autoras plantearon que este era un hombre auto-actualizado que asumió su responsabilidad social y compromiso político, así uniendo su vida privada con las responsabilidades de su proyecto político o social. La

\footnotetext{
${ }^{36}$ Valentina Arcos, Ana Julia Cienfuegos, Cristina Monelli, "Represión y daño psicológico: Respuesta subjetiva frente a la ruptura de un proyecto político", manuscrito de seminario, Fundación Vicaría de la Solidaridad, marzo de 1980, ficha 001569; Ana Cienfuegos y Cristina Monelli, "El testimonio como instrumento terapéutico al nivel individual y social", manuscrito, ficha 002057, Archivo Vicaría de la Solidaridad, Santiago, abril de 1980. Las autoras desarrollan el concepto del hombre concreto en el manuscrito de seminario y luego lo aplicaron a su estudio sobre el testimonio. Publicaron bajo pseudónimos para evitar la persecución de la dictadura. Cienfuegos (Eugenia Weinstein) y Monelli (Elizabeth Lira) formaron parte del Programa Salud Mental FASIC. Información sobre los pseudónimos, y el permiso para publicarlos, se encuentran en una conversación personal por email con Elizabeth Lira, junio de 2013.

${ }^{37}$ Cienfuegos y Monelli, op.cit., 17-18. Paz Rojas también enfatizó el rol de la denuncia en la curación psicológica y su conexión con reparar la subjetividad política en una entrevista personal, Santiago, mayo de 2013.
} 
dictadura trató de destruir a este hombre, principalmente a través de la tortura. El trauma se seguiría expresando en forma psicosomática, como cefaleas, dolores musculares, problemas sexuales, dolores de estómago u otras enfermedades. Sobre la base de los escritos existencialistas, las autoras postularon que el testimonio formó parte del proceso que llamaron la "dialéctica del individuo" o la reconstrucción del yo: la integración de las experiencias del pasado con el presente para planificar el futuro. Ese proceso dialéctico fue fundamental para la realización del hombre concreto ${ }^{38}$.

De acuerdo a las autoras, después del encarcelamiento, la tortura y el desempleo de larga duración resultante de las listas negras políticas, "el hombre adulto, de activa participación social y política, se ve reducido al espacio privado de su familia"39. La vida familiar tendía a estar llena de conflictos debido a situaciones inciertas y a la reconfiguración de los roles de género producto de la represión política. Otros estudios de salud mental mostraron que los hombres tenían grandes dificultades para adaptarse a los cambios, no sólo en su vida pública, sino también en su vida privada. Muchas mujeres comenzaron a trabajar fuera del hogar (muchas de ellas por primera vez en su vida) durante el encarcelamiento de sus maridos. Ellas siguieron trabajando cuando sus maridos no podían encontrar trabajo después de regresar a casa, convirtiéndose en el principal sostén y tomando decisiones sobre el manejo del hogar y la crianza de los hijos. Las mujeres se acercaron a las ollas comunes, a la comunidad y a las organizaciones de derechos humanos. Muchas encontraron un sentido de autonomía e independencia a pesar de encontrarse en situaciones inquietantes y aterradoras. También empujaron a sus maridos, hijos y otros familiares varones a buscar terapia ${ }^{40}$.

A nuestro parecer, mientras que los profesionales de la salud mental y la comunidad de derechos humanos en general elogiaron a las mujeres por su participación activa, dicha participación también se percibió, de forma implícita, como una amenaza a la masculinidad de los hombres de izquierda. A nuestro juicio, el "hombre concreto" era una conceptualización masculina del yo. Las autoras citaron específicamente las políticas de la Unidad Popular que ligaban la participación política de los hombres con su rol de proveedor del hogar. Además, el concepto reproduce las ideas del género prevalecientes en la psiquiatría y psicología que asociaron la esfera pública con el hombre y la esfera privada con la mujer. Las autoras destacaron que el "hombre concreto" no estaba completo a menos que participara activamente en la esfera pública y social. El método del testimonio oral proporcionó un medio para que los ex presos políticos reconstruyeran sus subjetividades

\footnotetext{
${ }^{38}$ Arcos, Cienfuegos y Monelli, op.cit.,1-9; Cienfuegos y Monelli, op.cit., 2-4, 14-16. Sobre el trauma, véase Cathy Caruth (ed), Trauma: Explorations in Memory, Baltimore, Estados Unidos, Johns Hopkins University Press, 1995; Ruth Leys: Trauma: A Genealogy, Chicago, University of Chicago Press, 2000.

39 Arcos, Cinfuegos y Monelli, op. cit., 9.

${ }^{40}$ Véase, por ejemplo, "Relegaciones: su impacto psicológico en las personas y en la familia", documento de trabajo, Fichas CD 2752.3 y 2462.3, Fundación Vicaría de la Solidaridad, Santiago, 1980; Aunque a muchas veces los profesionales no tendían a analizar las acciones de las mujeres como ejercicios de agencia especificamente, algunos trabajos las destacan de manera más explícito, por ejemplo CODEPU-DITT, "Estudio evolutivo del efecto de la tortura en la familia", documento de trabajo, versión revisada, Biblioteca CINTRAS, Santiago, 16 de marzo de 1989.
} 
políticas y personales al poner en palabras una experiencia traumática, organizar su significado e integrarla en la narrativa de su vida. La alternativa era relegar la experiencia a un paréntesis que los pacientes negaban o eran incapaces de reconocer conscientemente, así impulsando el retiro a la esfera privada y el quiebre de lazos sociales y políticos. Los estudios sobre el hombre concreto, entonces, reafirmaron la inquietud de que si el liderazgo de la izquierda se había retirado a la esfera privada, entonces la lucha contra la dictadura y la restauración de la democracia resultaría difícil ${ }^{41}$.

\section{La tortura sexual, lo normal y lo anormal}

Para demostrar la tortura extrema que sus pacientes experimentaron, así como la recuperación psíquica que el método del testimonio facilitaba, Cienfuegos y Monelli optaron por el estudio del caso de un preso de veinte y siete años de edad que había vivido y presenciado la tortura sexual. Debido a que el paciente había expresado su preocupación por la disminución del interés sexual y problemas de impotencia, exploraron la cuestión y encontraron que había sido sodomizado con una picana eléctrica y que fue testigo de la violación en grupo y la tortura sexual a mujeres mientras estaba encarcelado. En el caso de este paciente, el torturador que lo violó era un hombre. En la presentación de los casos, las autoras describieron la picana como "un pene metálico al cual se daba corriente". Tanto el acto de la penetración de un instrumento en forma de pene, así como la ejecución de la tortura sexual por un hombre fueron calificados como tortura "homosexual" en lugar de sodomía o violación ${ }^{42}$.

Los torturadores le habían presentado una decisión imposible: informar sobre sus compañeros, estar sometido a la sodomía dolorosa y humillante, o ser testigo de los sufrimientos y posible muerte de su hermano. Dos militares insertaron una picana en el recto y le dieron corriente a ese hombre durante horas, junto a su hermano. Amenazaron al preso político con sodomizarlo y electrocutarlo con una picana más grande si no hablaba, y uno le dijo, "Las mujeres gozan con este, así que imagínate cómo vas a gozar vos". 43 Finalmente, cuando el preso político ya no podía soportar ser testigo de los sufrimientos de su hermano, les dijo a los torturadores que iba a hablar de una lista que contenía los nombres de algunos de sus compañeros. Por tanto, a nuestro juicio, este pasaje muestra la falsa dicotomía implicada en la decisión de hablar o no hablar sobre los compañeros, lo cual se llama popularmente "delación".

Monelli y Cienfuegos habían declarado anteriormente en el informe que "la vejación, las experiencias sexuales denigrantes o aberrantes $\mathrm{y}$, finalmente, en no pocos casos, la delación como resultado de un sufrimiento físico y psicológico intolerante, son hechos difícilmente comunicables"44. Para muchos militantes, especialmente los hombres, el sufrimiento emocional era una señal de debilidad e inestabilidad, lo opuesto a la fuerza

\footnotetext{
${ }^{41}$ Arcos, Cienfuegos y Monelli, op. cit.; Cienfuegos y Monelli, op. cit.

${ }^{42}$ Cienfuegos y Monelli, op.cit., Anexo II, 1-2.

${ }^{43}$ Cienfuegos y Monelli, op.cit., Anexo II, 12.

${ }^{44}$ Cienfuegos y Monelli, op.cit., Anexo II, 2.
} 
masculina del héroe revolucionario. Sin embargo, como este paciente reveló en su testimonio cuando estaba a punto de salir de Chile hacia el exilio:

Es que dentro de la ley uno no debiera ni siquiera conmoverse con todo lo que estaba viviendo, no quebrarse, uno tiene que mantenerse entero, alerta, por eso yo creo--y eso ha pasado con todos los compañeros-que rechazamos una pastilla para dormir porque no queremos dormir, de ahí que rechazamos el declarar, yo por mí, me hubiese guardado toda la vida esas cosas, que por culpa mía cayeron unos compadres, indirectamente soy motivo de un desaparecido. Eso me agobia mucho.

No viví toda esa experiencia solo, sí gran parte la he vivido solo, me he topado con gente que no estaba en mi misma condición, pero sí que esto no va a ser en vano, porque esto me ha hecho madurar y mantenerme firme en mi posición. Para qué vamos a hablar de odios y rencores, que las cosas se den, bueno, que se den con un buen desenlace, o como sea, pero la cosa es que hay que empujar por Chile, aunque sea desde afuera ${ }^{45}$.

Este caso ilumina las tensiones existentes en las arraigadas creencias acerca de la masculinidad porque, tal como el paciente expresa, algunas ideas sobre la masculinidad militante trazaron paralelos entre silenciar el sufrimiento de uno, tanto dentro de la prisión como fuera. El partido de este militante esperaba que los militantes soportaran la tortura, estuvieran alertas y mantuvieran el silencio para proteger a sus compañeros-y quizá también para dar testimonio de lo que pasó con los demás. La incapacidad para resistir o silenciar el sufrimiento emocional durante o después de la cárcel señalaba la inestabilidad y la falta de credibilidad. Sin embargo, los autores destacaron que el paciente llegó a aceptar que el camino hacia la estabilidad emocional era a través de hablar de sus experiencias. Hablar de su sufrimiento, a pesar de que contradijera "la ley" (probablemente una referencia a la doctrina o prácticas de un grupo de izquierda, o alternativamente, el sentido común sobre la masculinidad) le había ayudado a recuperar su salud mental y reforzar sus creencias políticas. Enfrentar su trauma también era parte integral de la construcción de un nuevo proyecto político: había realizado conexiones con un grupo político en el exilio y continuó su lucha por lo social.

Cuando habló de su tortura, este ex preso político, de diversas maneras, expresó sentimientos de perder su sentido de sexualidad (heterosexual) masculina. Asimismo, hablar de estos sentimientos sugiere que, en algunos contextos-como la terapia psicológica con terapeutas empáticos - empezaba una erosión de las nociones de la masculinidad que prescribían el estoicismo duro al enfrentar el dolor físico y emocional. Sin embargo, el "hombre concreto" cuya reconstrucción las autoras propusieron a través de la curación psicológica, fue un concepto basado en nociones arraigadas del heteropatriarcado. Esto, sostengo, podría haber reforzado (seguramente sin intención) el silenciar

${ }^{45}$ Cienfuegos y Monelli, op.cit., Anexo II, 27. 
el mismo sufrimiento que las autoras y otros profesionales de la salud mental buscaron deshacer.

No obstante, este caso de estudio y el testimonio del ex preso político no solamente tuvieron el efecto de denunciar las graves violaciones de los derechos humanos; también demostró que hablar, escribir y denunciar fueron centrales tanto a la rehabilitación de la subjetividad personal como a la recuperación de la democracia. Fue un recordatorio importante en un momento en el cual algunos presos políticos sobrevivieron la tortura habiendo mantenido el silencio, mientras otros sufrieron un sentido de profunda culpabilidad por haber hablado de sus compañeros. Además, en aquel momento, pocas personas habían hablado de la tortura sexual, aún menos los hombres, por la humillación que este tipo de tortura provocaba.

Mientras que los profesionales reconocieron la tortura sexual en términos generales como una perversión del poder que distorsionó el acto sexual al eliminar el poder o el consentimiento de la víctima, se definieron las "prácticas homosexuales" de la tortura como desviadas. Además, encontraron que "la tortura homosexual" o "prácticas homosexuales" en la tortura sexual de los hombres destruyeron la autoestima de la víctima y la capacidad de confiar en otros, y potencialmente inhibió su función sexual. En los pocos estudios de la época que abordaban la tortura sexual contra los hombres, la mayoría de los profesionales categorizaron la sodomía con objetos (como la picana), la penetración del pene y la masturbación de los presos como "tortura homosexual." Cuando se trató de la desnudez forzada, acoso sexual (por ejemplo, llamar a los hombres "maricones" o antagonizarlos acerca de su sexualidad o la de una mujer amada), la electrocución en los genitales y / o en el ano y golpes en los testículos acompañados por sodomía o masturbación, los terapeutas y los pacientes tendían a clasificar las torturas como sexuales, u homosexuales. Sin embargo, si un preso político masculino informó sólo la golpiza y la electrocución en los genitales, por ejemplo, los trabajadores de derechos humanos y / o profesionales de salud mental tendían a categorizar esos actos como "tortura física" y no "tortura sexual". 46 De esta manera, tendieron a invisibilizar la tortura sexual en contra a los hombres por la dificultad de comprenderla/encuadrarla dentro los esquemas de género dominantes.

Tal como en el caso del ex preso político presentado al principio de este artículo, la mayoría de los hombres que informaron de la sodomía, violación, o la masturbación por agentes masculinos del estado etiquetaron a sus torturadores como homosexuales, tal vez en un intento de preservar su dignidad masculina y revertir la vergüenza y el discurso denigrante que el régimen había ejercido en sus cuerpos y psiques. Tanto la derecha como la izquierda consideraron la homosexualidad como una perversión que confundió el deseo entre personas del mismo sexo con el peligro y abuso de una persona sobre el cuerpo de otra. Esta conceptualización planteó la noción del deseo como peligro y violencia, en lugar de denunciar las acciones mismas de la violación, el abuso y el acoso sexual. Al mismo

\footnotetext{
${ }^{46}$ Algunos ejemplos incluyen Mario Insunza B. y Manuel Almeyda M., "Efectos físicos y psicológicos de los tratos crueles y degradantes", documento de trabajo, Archivo Vicaría de la Solidaridad, Santiago, ca,1983; Vicaría de la Solidaridad, "La práctica de la tortura en Chile durante 1984", Archivo y Biblioteca FASIC, Santiago de Chile, 1986.
} 
tiempo, si consideramos la historia de las actitudes acerca de la homosexualidad, tanto en la política como en las disciplinas de la salud mental, podemos ver por qué los ex presos políticos y varios terapeutas parecían carecer de un marco de entendimiento, o por lo menos de expresión, de la tortura sexual de los hombres por otros hombres.

Los equipos de salud mental y de medicina parecían asociar actos como electrocución en los genitales, y la tortura sexual en general, principalmente como una amenaza a los cuerpos y la sexualidad de las mujeres. La violación y la tortura sexual de las mujeres fue más imaginable, aunque terrible: era un tropo de la guerra, además de una extensión de la violencia masculina contra las mujeres en la sociedad. De hecho, los autores del Informe Valech vincularon la tortura sexual de las mujeres a la guerra, no metafóricamente, sino en un sentido concreto. La agresión de los hombres contra otros hombres en la forma de tortura no sexualizada era concebible como una extensión de la agresión masculina contra otros hombres, y como la realidad de la guerra ${ }^{47}$. Sin embargo, la tortura sexual de hombres contra hombres no tenía cabida en los tradicionales arquetipos bélicos, y era difícil de conceptualizar sin alterar los esquemas de género que compartían terapeutas y pacientes.

A diferencia de publicaciones y documentos de trabajo de FASIC y la Vicaría, los del equipo de CODEPU muestran un entendimiento menos heteronormativo en sus informes sobre la tortura sexual contra hombres y mujeres. En 1976, las profesionales de salud mental que luego fundarían CODEPU-DITT (equipo para la "Denuncia, Investigación y Tratamiento al Torturado y su Núcleo Familiar) en 1980, presentaron sus hallazgos sobre los tres primeros años de la dictadura en la ceremonia de apertura del Año del Prisionero de Opinión de Amnistía Internacional. Basaron su estudio en 58 casos de presos políticos, y destacaron que tanto mujeres como hombres experimentaron "los malos tratos físicos, aplicados. . . con la misma intensidad”. Es más, en cuanto a la tortura sexual, sostuvieron, "Esta forma de tortura se ha mantenido constantemente durante los tres años, y la mitad de los presos, sin distinción de sexo, son sometidos a ella"48. En esta ponencia y otra publicación de la misma época, señalaron que la tortura sexual de hombres no fue una anomalía, sino sistemática, tal como en el caso de las mujeres. Los métodos de tortura sexual fueron presentados sin ligarlos a la noción del deseo sexual. Por ejemplo, no usaron el término "tortura homosexual", sino que describieron el carácter físico de los métodos, tal como "penetración anal con picana". Es decir, la tortura sexual contra los hombres, ejecutada ya sea por hombres o por mujeres, fue representada dentro de un rango de prácticas de tortura sexual bajo una dictadura que trató de destruir subjetividades

\footnotetext{
${ }^{47}$ Comisión Nacional sobre la Prisión Política y la Tortura, Informe de la Comisión Nacional sobre la Prisión Política y la Tortura, Santiago, 2004, 290.

48 "La tortura en Chile: Técnicas y efectos", ponencia presentada en la ceremonia de apertura del Año del Prisionero de Opinión de Amnistía Internacional, Fundación Vicaría de la Solidaridad, Santiago de Chile, 1976. Aunque el documento no nombra autor, información de otros documentos y de una entrevista personal con Paz Rojas de CODEPU (mayo de 2013), confirman que el autor/los autores fueron los mismos profesionales de la salud mental que luego fundaron CODEPU-DITT.
} 
individuales y vínculos sociales. En publicaciones sucesivas, utilizaron este mismo modo de describir y analizar la tortura sexual ${ }^{49}$.

En contraste con la dificultad que los profesionales de la salud mental tuvieron para abordar a violencia política sexual contra los hombres, parecen haber tenido un marco de referencia para abordar la violencia contra mujeres. Por ejemplo, un grupo de sociólogos escribió un informe para el Comité Pro-Paz en 1975 sobre los efectos de la violencia de la dictadura en las mujeres. En su gran mayoría, el informe destacó el peligro que impuso el régimen al cuerpo femenino como portador de vida y cuidadora de los niños. Aunque presentaron casos de mujeres militantes, los autores se centraron en las mujeres que fueron detenidas, torturadas y violadas para amenazar a los miembros varones de sus familias que eran militantes. Subrayaron la tortura de las mujeres embarazadas y mujeres que eran madres y esposas. Al tiempo que citaron estadísticas de cuántas mujeres casadas, madres y mujeres embarazadas fueron detenidas y torturadas, no ofrecen estadísticas sobre las mujeres solteras o sin hijos - o por lo menos, esta información no es explícita. Informes posteriores de otras organizaciones también enfatizaron la tortura de las mujeres embarazadas y las madres y el encarcelamiento de niños junto a sus madres ${ }^{50}$. Ahora bien, es preciso destacar que fueron las feministas y las mujeres ex presas políticas que iluminaron, y siguen iluminando, la sistematización de la tortura sexual contra las mujeres. De hecho, una sección especial del Informe Valech destacó la tortura sexual de las mujeres embarazadas como preocupación central en la investigación de la Comisión sobre la tortura sexual de las mujeres. Probablemente sin intención, los autores supusieron y reforzaron nociones de la maternidad como objetivo primordial de la mujer, así como la permeabilidad y la debilidad de los cuerpos de las mujeres frente a la agresión y la indestructibilidad del cuerpo masculino ${ }^{51}$.

El revelar la comprensión subyacente de un binario de género sobre la agresión masculina y la vulnerabilidad femenina que compartían los profesionales de la salud y sus pacientes también nos permite comprender testimonios de ex presos políticos que parecían sorprendidos de que las mujeres fueran torturadoras más crueles que los hombres y demostraban más placer en su trabajo. Es difícil saber si las mujeres torturadoras eran en realidad más violentas que sus colegas varones, o si parecían más crueles y frías a los prisioneros porque la mujer torturadora contradecía el papel convencional de la mujer débil, sensible y maternal. La tortura era una exageración extrema de la agresión masculina y por

\footnotetext{
${ }^{49}$ Véase: Katya Reszczynski, Paz Rojas y Patricia Barceló, Tortura y resistencia en Chile. Estudio médicopolítico, Santiago, Editorial Emisión, 1991, 134-178. Las autoras terminaron de escribir este libro en 1978 mientras refugiadas en Paris, Francia. Publicaron el libro originalmente en Francia en 1984. Después de volver a Chile establecieron el equipo de salud mental CODEPU-DITT en 1980. La publicación del libro en 1991 fue la primera edición en Chile y en castellano, y en 2013 el editorial de la Universidad de Chile hizo una re-edición de ese. Reszczynski, Rojas y Barceló, op.cit, 5; Entrevista personal con Paz Rojas, mayo de 2013.

${ }^{50}$ Comité Pro-Paz, "La situación general de la mujer bajo el Gobierno Militar de Chile," 1975, documento de trabajo, Fundación de Documentación y Archivo de la Vicaría de la Solidaridad, Santiago de Chile; Comisión Nacional sobre la Prisión Política y la Tortura, op.cit., 575-580.

${ }^{51}$ Ibídem; Hiner, op. cit., 50-74; Informe de Comisión de la Prisión Política y Tortura, 290-297.
} 
lo tanto más fácil para los presos de comprender en forma masculina. Es claro, sin embargo, que las mujeres no eran siempre las víctimas de los hombres, sino también sus victimarios. En el mismo informe del COLAT citado anteriormente, un ex preso político reflexionó:

El problema de las mujeres que torturan es impresionante también. Impresionante porque uno llega por último a justificar, haciendo bastantes abstracciones de que un hombre; digamos un ente político, pudiera llegar a caer en una desviación como la que tienen esta gente de la DINA con las mujeres nuestras, con las compañeras. Pero resulta difícil concebir que una mujer llegue a tener esa misma desviación para con nosotros los hombres. Es decir, yo podría entender que los torturadores por su falta de ideología, su nivel cultural escaso, el entrenamiento brutal que le hacen en alguna parte, por todas esas condiciones no tienen nada en la cabeza que les haga pensar si lo que hacen es bueno o malo, que hagan cualquier tipo de aberración sexual con las compañeras nuestras. A mí no me cabía en la cabeza el problema de las mujeres que están en los equipos de interrogadores ${ }^{52}$.

Este hombre que fue torturado por agentes mujeres de la DINA se dio cuenta de que no todas las mujeres eran como sus compañeras. En su testimonio, el ex preso contó que había creído previamente que sólo los hombres eran capaces de ser corrompidos por el régimen y convencidos de cometer atroces actos violentos de la "desviación", especialmente si carecían de la "cultura" para pensar por sí mismos, y para frenar la agresión. Además, le hizo más sentido que los agentes hombres violaran y torturaran sexualmente a las mujeres compañeras, mientras que no le "cabía en la cabeza" que las mujeres pudieran ser autoras de la violencia de Estado, tanto como sus víctimas. En su perspectiva, la conducta adecuada de las mujeres se relacionaba con la norma social que ve a las mujeres como guardianas de la decencia sexual, víctimas de la violencia sexual y seres incapaces de participar en la violencia brutal. Por tanto, las agentes mujeres de la DINA, a través de la violencia sancionada por el estado, no sólo violaron su integridad, sino que destruyeron el mundo en el cual los hombres tenían el poder sexual, social y político sobre las mujeres, incluso dentro de los partidos políticos de la izquierda ${ }^{53}$.

En lugar de analizar las construcciones de género que informaron el testimonio del paciente, el objetivo principal de los autores por destacar este caso era demostrar que existían mujeres torturadoras y, al igual que agentes de la DINA masculinos, torturaron sexualmente a los presos políticos varones. Mientras que los autores solo hicieron breves comentarios y en gran medida permitieron que los testimonios hablaran por sí solos, concluyeron que el ser torturado por una mujer, especialmente con torturas sexuales, provocó un "shock emocional" en el hombre que ellos "no podían analizar con precisión en

\footnotetext{
52 COLAT, op. cit., 22.

${ }^{53}$ Véase: Julieta Kirkwood, Ser política en Chile. Las feministas y los partidos, tercera edición, Santiago, LOM, 2010,154-166.
} 
el momento"54. La incapacidad del equipo de desmontar la situación en lo que fue una denuncia de violaciones de derechos humanos, además de una obra intelectual del equipo de COLAT, no sólo apunta cuán profundamente las ideas sobre los hombres violentos y mujeres vulnerables estaban arraigadas en el sentido común, sino que también reafirmaron esos conceptos mismos, implícitamente y probablemente sin querer.

Por otra parte, mediante la presentación de testimonios de un hombre torturado sexualmente por una mujer y de un hombre torturado sexualmente por un hombre, COLAT buscaba iluminar situaciones que aún no habían sido estudiadas, quizá ni siquiera imaginadas, en el caso de Chile, ni tampoco en el de América Latina. Mientras que la mayoría de los militantes y organizaciones de derechos humanos consideraba que las mujeres fueron más expuestos a sufrir la tortura sexual (y rara vez o nunca sus autoras), el equipo de COLAT mostró que los agentes represivos del estado estaban, de verdad, torturando sexualmente a los hombres. Permitió, asimismo que al menos algunos hombres, hablaran de ello, abriendo así la vía futura para una comprensión más compleja de la violencia sexual.

\section{Conclusión}

En agosto de 2015, los ex presos políticos Samuel Houston y René Lizama denunciaron a varios agentes de la DINA por ejercer el abuso sexual (entre otras torturas) contra ellos en los recintos de Londres 38 y Tejas Verdes. En la querella por "abusos deshonestos", la eufemística categoría legal que utiliza para referirse a la violencia sexual, citaron el coraje de las ex presas políticas que, mucho antes que ellos, la habían denunciado. Houston y Lizama también destacaron la necesidad de "romper con la cultura 'machista' de los ex presos políticos varones, a los cuales tanto nos cuesta tanto hablar de este tema". Señalaron que la tortura sexual contra los hombres era más prevaleciente que lo que se creía hasta entonces, y que los hombres deberían "romper su silencio y denunciar estos crímenes de lesa humanidad", e incorporar estas experiencias en la memoria histórica55.

Este artículo no ha sido un esfuerzo para determinar quién, si los hombres o las mujeres, sufrieron más la tortura sexual. Más bien, junto con otros autores, sostengo que tales preguntas perpetúan el mito de que la única o principal amenaza a la sexualidad de los hombres de izquierda fue su papel como protectores y proveedores de las mujeres, que los hombres eran invulnerables a la violación y sólo las mujeres fueron tan débiles y sus cuerpos suficientemente permeables para que una amenaza tan grande sobre sus cuerpos fuera posible. Ser hombre y ser violado sexualmente significaría "bajar" al nivel de la

\footnotetext{
${ }_{55}^{54}$ COLAT, op.cit.

55 "Presentan nueva querella querella de secuestros y torturas contra cúlpula de la DINA", https://villagrimaldi.cl/noticias/presentan-nueva-querella-querella-por-secuestro-y-torturas-contra-cupula-dela-dina/; Véase también:, "Querella criminal post mortem a Manuel Contreras y sus secuaces por abuso sexual contra hombres en la tortura", El Ciudadano, 12 de agosto de 2015, https://www.elciudadano.cl/justicia/querella-criminal-post-mortem-a-manuel-contreras-y-sus-secuaces-porabuso-sexual-contra-hombres-en-la-tortura/08/12/.
} 
supuesta debilidad de una mujer. Este estudio ha tratado de analizar el significado de género en la violencia sexual, no de crear una escala en la gravedad del sufrimiento.

Las mujeres que fueron torturadas sexualmente por los agentes del régimen de Pinochet han encontrado un espacio para hablar de sus experiencias - un espacio que el feminismo, las organizaciones de mujeres, las organizaciones de derechos humanos, la izquierda, el estado democrático y, obviamente, las mismas mujeres sobrevivientes han creado y reforzado. Muchas mujeres han encontrado que hablar de la tortura sexual ha invertido la humillación que la dictadura trató de imponer sobre ellas ${ }^{56}$. En cambio, la tortura sexual de los hombres, así como los problemas psicosexuales resultantes de ella, no era funcional a los fines de la reconstrucción de la izquierda o el estado democrático como entidades políticas masculinas. En los informes Rettig y Valech, por ejemplo, el Estado no tuvo en cuenta la impotencia que generó en los hombres la represión económica, al igual que no vinculó las consecuencias de la violencia política en problemas estructurales más profundos de la vida cotidiana, como el sufrimiento económico, la violencia doméstica, y el alcoholismo. No se ha integrado ni transformado la tortura sexual contra los hombres en una narrativa de heroísmo o como parte de ser un "soldado en la guerra", como sí se hizo con otras formas de tortura como corriente eléctrica y golpes. Además, utilizando el mismo lenguaje que los profesionales de la salud mental de los años ochenta, al describir la tortura sexual y sus consecuencias extensas, los autores del Informe Valech hablaron de "las violaciones hetero y homosexuales," para señalar que los hombres también sufrieron torturas y violaciones sexuales cometidos por otros hombres ${ }^{57}$.

Varios profesionales de la salud mental y sus pacientes relacionaron la tortura sexual de los hombres a la homosexualidad, lo cual patologizó el deseo por el mismo sexo al combinarlo con la violencia. Al mismo tiempo, estas definiciones de la sexualidad "normal" y "anormal", basados en binarios de hombre/mujer y homosexualidad/heterosexualidad, fueron parte de una larga tradición que constituyeron a lo largo del siglo XX una parte central de los saberes de las disciplinas de la salud mental. Asimismo, las culturas políticas de la izquierda fueron moldeadas por ideas de género y sexualidad que definieron el rol de los hombres como jefes de hogar y protagonistas políticos y el de las mujeres como madres, esposas y compañeras. Además, excluyeron, ya sea retóricamente o en las prácticas políticas, la homosexualidad masculina. Como los pacientes hablaron de sus experiencias y llamaron homosexuales a sus torturadores, buscaron reforzar su propia masculinidad heterosexual y la de la izquierda. Asimismo, los profesionales de la salud mental que utilizaron categorías como "tortura homosexual" o "prácticas homosexuales" en relación con la violencia de Estado reforzaron creencias heteronormativas y patriarcales para reconstruir las subjetividades personales y políticas de los y las víctimas.

Esto no quiere decir que los profesionales de la salud mental tenían la intención de denigrar a las personas LGBT, ni tampoco que perpetuaron a propósito un sistema de poder

\footnotetext{
${ }^{56}$ Temma Kaplan, "Acts of Testimony: Reversing the Shame and Gendering the Memory”, Signs 28, Autumn 2002, 179-199.

${ }^{57}$ Hiner, op.cit.; Informe de la Comisión Nacional sobre la Prisión Política y la Tortura, 290, 604.
} 
en que los hombres dominaban a las mujeres. Más bien, los profesionales de la salud mental buscaban llamar la atención sobre la violencia de Estado a través de estudios de caso, denunciar violaciones de derechos humanos, ayudar a las víctimas de la violencia estatal a recuperarse del trauma y hacer un aporte en la lucha por la democracia a través de su trabajo. Sin embargo, las nociones preconcebidas acerca de la relación entre la participación política, la sexualidad, el género y el orden de la sociedad influyeron en sus conceptos y prácticas. Aunque las fuentes analizadas en el presente texto son de fecha anterior a los grandes movimientos por los derechos LGBT en Chile, es necesario cuestionar los supuestos que formaron sus valores culturales y sociales con el fin de entender los efectos que tuvieron en sus intervenciones terapéuticas y políticas. También es fundamental para la comprensión y la realización de cambios históricos, y para abrir espacios para que los ex presos políticos y torturados puedan hablar sobre el pasado.

Esto tampoco quiere decir que cada persona, hombre o mujer, que fue torturada sexualmente debe hablar de ello, o que la heteronormatividad y el patriarcado son los únicos factores que han silenciado a los que sufrieron la violencia de Estado. Con todo, estas estructuras de poder juegan un papel innegable en tomar la decisión de hablar, y en avergonzar tanto a hombres como a mujeres que fueron víctimas de tortura sexual.

También han sofocado, y seguramente siguen silenciando, muchas voces de sobrevivientes LGBT de la tortura: ninguno de los documentos encontrados durante esta investigación contenían testimonios de mujeres u hombres que se identificaron como lesbianas, gays, bisexuales o transexuales. Pero eso no quiere decir que las personas LGBT no hayan experimentado la violencia de Estado y que después hayan buscado tratamiento de salud mental. Tal vez ellos no revelaran su identidad sexual o de género a los terapeutas, o quizá estos últimos no contaran esos detalles en los estudios de caso. Mirando hacia adelante en nuestras investigaciones sobre la dictadura, es fundamental que seamos conscientes sobre las ideas de género y la sexualidad que dieron forma a cómo los actores históricos hablaron y escribieron acerca de la violencia de estado-y lo que tal vez silenciaron - para que podamos entender el impacto de esos conceptos en el discurso de los derechos humanos, así como la memoria histórica.

\section{Bibliografía}

\section{Archivos}

Archivo y Biblioteca Fundación de Ayuda Social de las Iglesias Cristianas (FASIC)

Archivo y Centro de Documentación Vicaría de la Solidaridad

Biblioteca del Centro de Investigación y Tratamiento del Stress (CINTRAS)

Biblioteca del Museo de Medicina Nacional Enrique Laval, Universidad de Chile

Biblioteca Nacional de Chile 
Brandi Townsend, Violentando y rehabilitando masculinidades de izquierda: La tortura sexual contra hombres y la terapia psicológica en las organizaciones de derechos humanos durante la dictadura de Pinochet, 1970s-1980s, Izquierdas, 43,

\section{Prensa}

"Presentan nueva querella querella de secuestros y torturas contra cúlpula de la DINA", https://villagrimaldi.cl/noticias/presentan-nueva-querella-querella-por-secuestro-y-torturas-contracupula-de-la-dina/, fecha de último acceso 31 de enero de 2018.

"Querella criminal post mortem a Manuel Contreras y sus secuaces por abuso sexual contra hombres en la tortura", El Ciudadano, 12 de Agosto de 2015, https://www.elciudadano.cl/justicia/querella-criminal-post-mortem-a-manuel-contreras-y-sus-

secuaces-por-abuso-sexual-contra-hombres-en-la-tortura/08/12/, fecha de ultimo acceso 31 de enero de 2018.

\section{Fuentes Primarias Publicadas}

CODEPU-DITT, Persona, Estado, Poder. Estudios sobre salud mental. Chile, 1973-1989, Santiago, Edición Sergio Pesutic, 1989.

Comisión Nacional sobre la Prisión Política y la Tortura, Informe de la Comisión Nacional sobre la Prisión Política y la Tortura, Santiago, 2004.

Guevara, Ernesto, "El hombre y el socialismo en Cuba", Estrategia: Revista Teórica, Movimiento de Izquierda Revolucionaria, Septiembre de 1966, 1-16.

Revista Chilena de Psiquiatría Clínica, Santiago, Universidad de Chile, años 1962-1979.

Reszczynski, Katya, Paz Rojas y Patricia Barceló, Tortura y resistencia en Chile. Estudio médico-político, Santiago, Editorial Emisión, 1991.

Roa, Armando, Nueva visión de las enfermedades mentales. Disfernias, personalidades paranormales, homosexualidad. Crítica al DSM II, Santiago, Editorial Universitaria, 1984.

Roa, Armando, Psiquiatría, Santiago, Editorial Andrés Bello, 1959.

\section{Bibliografía Citada}

Agger, Inger, "Sexual Torture of Political Prisoners: An Overview", Journal of Traumatic Stress 2:3, 1989, 305-314.

Barr-Melej, Patrick, Psychedelic Chile: Youth, Counterculture, and Politics on the Road to Socialism and Dictatorship, Chapel Hill, University of North Carolina Press, 2017.

Bunster-Burotto, Ximena, "Surviving Beyond Fear: Women and Torture in Latin America", June Nash y Helen I. Safa (eds), Women and Change in Latin America, South Hadley, Massachusetts, Estados Unidos, 1986, 297-395.

Butler, Judith, Gender Trouble, tercera edición, New York, Routledge, 2006. Press, 1995.

Caruth, Cathy (ed), Trauma: Explorations in Memory, Baltimore, Johns Hopkins University

Cornejo, Juan Rolando, "Configuración de la homosexualidad medicalizada en Chile", Sexualidad, salud y sociedad 9, Rio de Janeiro, enero de 2011.

Deutsch, Sandra McGee, "Gender and Sociopolitical Change in Latin America", Hispanic American Historical Review 71:2, May 1991, 259-306.

Drescher, Jack, "Out of DSM: Depathologizing Homosexuality", Behavioral Sciences 5:4,

Basel, Suiza, December 2015, 565-575, disponible en: https://www.ncbi.nlm.nih.gov/pmc/articles/PMC4695779/

Foucault, Michel, History of Sexuality, Volume I: An Introduction, segunda edición, New York, Vintage, 1980.

Garcés, Mario y Nicholls, Nancy, Para una historia de los derechos humanos en Chile. Historia institucional de la Fundación de Ayuda Social de la Iglesias Cristianas, 1975-1991, Santiago, LOM, 2005. 
Brandi Townsend, Violentando y rehabilitando masculinidades de izquierda: La tortura sexual contra hombres y la terapia psicológica en las organizaciones de derechos humanos durante la dictadura de Pinochet, 1970s-1980s, Izquierdas, 43, diciembre 2018:159-184

Hiner, Hillary, "Voces soterradas, violencias ignoradas: Discurso, violencia política, y género en los Informes Rettig y Valech", Latin American Research Review 44:3, November 2009, 50-74.

Hollander, Nancy Caro, Love in a Time of Hate: Liberation Psychology in Latin America, New Brunswick, Rutgers University Press, 1997.

Illanes, María Angélica, "La 'pedagogía crítica' de las trabajadoras sociales en el Chile de los sesenta y setenta", Mujeres. Historias chilenas del siglo XX, Julio Pinto Vallejos (ed.), Santiago, LOM, 2010, 9-34.

Illanes, María Angélica, Cuerpo y sangre de la polítia: La construcción social de las Visitadoras Sociales, 1887-1940, Santiago, LOM, 2007.

Kaplan, Temma, "Acts of Testimony: Reversing the Shame and Gendering the Memory", Signs 28, Autumn 2002, 179-199.

Kirkwood, Julieta, Ser política en Chile. Las feministas y los partidos, tercera edición, Santiago, LOM, 2010.

Leys, Ruth, Trauma: A Genealogy, Chicago, University of Chicago Press, 2000.

Mallon, Florencia, "Barbudos, Warriors, and Rotos: The MIR, Masculinity, and Power in the Chilean Agrarian Reform, 1965-75", Matthew C. Gutmann (ed), Changing Men and Masculinities in Latin America, Durham, Duke University Press, 2003, 179-215.

Power, Margaret, "La Unidad Popular y la Masculinidad", La ventana 6, 1997, 250-270.

Rosemblatt, Karin, Gendered Compromises: Political Cultures and the State in Chile, 1920- 1950, Chapel Hill, University of North Carolina Press, 2000.

Rosemblatt, Karin, "Sexuality and Biopower in Chile and Latin America", Political Power and Social Theory 15, 2002, 229-262.

Ruíz, Olga, "Mandatos militantes, vida cotidiana y subjetividad revolucionaria en el Movimiento de Izquierda Revolucionaria de Chile (1965-1975), Revista Austral de Ciencias Sociales 28, 2015, 163-182.

Salgado, Alfonso, "A Small Revolution: Family, Sex, and the Communist Youth of Chile during the Allende Years (1970-1973)," Twentieth Century Communism 8, January 2015, 62-88.

Tinsman, Heidi, Partners in Conflict: The Politics of Gender, Sexuality, and Labor in the Chilean Agrarian Reform, 1950-1973, Durham, Duke University Press, 2002.

Valdés, Teresa, Centros de Madres, 1973-1989. Sólo disciplinamiento? Santiago, FLACSO, 1989.

Vaughan, Mary Kay, "Modernizing Patriarchy: State Policies, Rural Households, and Women in Mexico, 1930-1940", Elizabeth Dore y Maxine Molyneux (eds), Hidden Histories of Gender and the State in Latin America, Durham, Duke University Press, 2000, 194-214.

Vëto, Silvana, "Higiene Mental Infantil y Psicoanálisis en la Clínica de Conducta, Santaigo de Chile, 1936-1938, ACSLEPIO: Revista de Historia de la Medicina y de la Ciencia, 69:2, juliodiciembre 2107, 1-17.

\section{Entrevistas orales}

Entrevista personal con Elizabeth Lira, Santiago, abril de 2013. Entrevista personal con Paz Rojas, Santiago, mayo de 2013. 